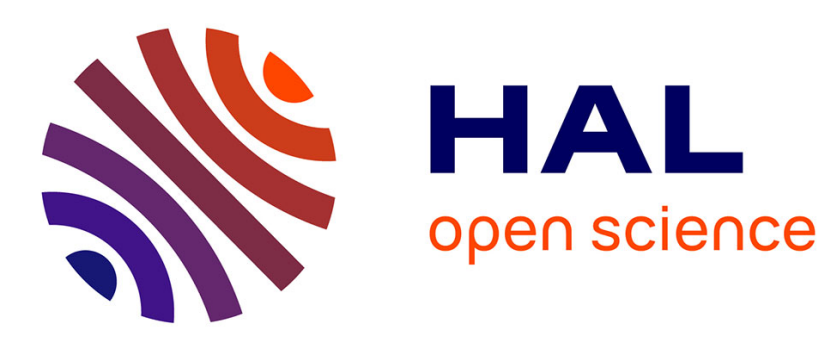

\title{
Recessed and P-GaN regrowth gate development for normally-off AlGaN/GaN HEMTs
}

Chaymaa Haloui, Toulon Gaëtan, Josiane Tasselli, Yvon Cordier, Éric

Frayssinet, Karine Isoird, Frédéric Morancho, Mathieu Gavelle

\section{- To cite this version:}

Chaymaa Haloui, Toulon Gaëtan, Josiane Tasselli, Yvon Cordier, Éric Frayssinet, et al.. Recessed and P-GaN regrowth gate development for normally-off AlGaN/GaN HEMTs. 28 International Conference MIXED DESIGN OF INTEGRATED CIRCUITS AND SYSTEMS, Jun 2020, Wroclow, Poland. hal02922723

\section{HAL Id: hal-02922723 \\ https://hal.laas.fr/hal-02922723}

Submitted on 1 Sep 2020

HAL is a multi-disciplinary open access archive for the deposit and dissemination of scientific research documents, whether they are published or not. The documents may come from teaching and research institutions in France or abroad, or from public or private research centers.
L'archive ouverte pluridisciplinaire HAL, est destinée au dépôt et à la diffusion de documents scientifiques de niveau recherche, publiés ou non, émanant des établissements d'enseignement et de recherche français ou étrangers, des laboratoires publics ou privés. 


\title{
Recessed and P-GaN Regrowth Gate Development for Normally-off AlGaN/GaN HEMTs
}

\author{
Chaymaa Haloui ${ }^{1,2}$, Gaëtan Toulon ${ }^{3}$, Josiane Tasselli ${ }^{1}$, Yvon Cordier ${ }^{4}$, Éric Frayssinet ${ }^{4}$, \\ Karine Isoird ${ }^{1}$, Frédéric Morancho ${ }^{1}$, Mathieu Gavelle ${ }^{2}$ \\ ${ }^{1}$ LAAS-CNRS, Toulouse University, CNRS, UPS, Toulouse, France \\ ${ }^{2}$ CEA Tech Occitanie, Toulouse, France \\ ${ }^{3}$ EXAGAN, Toulouse, France \\ ${ }^{4}$ CRHEA-CNRS, Valbonne, France \\ chaloui@laas.fr
}

\begin{abstract}
A new normally-off AlGaN/GaN HEMT structure is proposed. The regrowth of a $\mathrm{P}-\mathrm{GaN}$ layer on the $\mathrm{AIGaN} / \mathrm{GaN}$ heterostructure after the gate recess allows the achievement of the enhancement mode. A shift in the threshold voltage to positive values has been proved through simulation results. A precise control of the etch depth for the gate recess is detailed.
\end{abstract}

Keywords-HEMT; normally-off; AlGaN/GaN; gate recess; RIE; P-GaN regrowth.

\section{INTRODUCTION}

$\mathrm{AlGaN} / \mathrm{GaN}$ high-electron mobility transistors (HEMTs) have attracted worldwide attention in power electronics as candidates for next-generation of high-speed switching devices. Thanks to the large electric field of $\mathrm{GaN}$ and the high carrier mobility and density in the two-dimensional electron gas (2DEG), AlGaN/GaN HEMTs can achieve high breakdown voltage and realize ultrahigh power density operation with low power losses.

While most of the demonstrated AlGaN/GaN HEMTs are inherently normally-on with a negative gate threshold voltage, normally-off mode is strongly demanded to fulfill the requirements of power electronics applications; normally-off devices are inherently secure and suitable for energy converters requiring specifically high system reliability. Several approaches, each with its own limitations, have been proposed to convert the inherent depletion mode (normallyon) into an enhancement one (normally-off). Fluorine plasma ion implantation [1], oxygen treatment [2], gate injection transistor (GIT) [3] and P-GaN gate [4] are the most developed ones. In this paper a structure that combines two approaches (recessed and $\mathrm{P}-\mathrm{GaN}$ regrowth gate) is presented. The use of a $\mathrm{P}-\mathrm{GaN}$ layer on the $\mathrm{AlGaN} / \mathrm{GaN}$ heterostructure under the gate contact region lifts up the band diagram, which causes the depletion of the 2DEG channel, even in the absence of external bias. First, the simulated performance of the new device will be presented, then an overview of the technological process mandatory to realize such a device will be proposed, with a particular focus on the gate recess step.

\section{THE Simulated STRUCTURE}

Numerical simulations were performed with Sentaurus TCAD tools in order to have an insight of the HEMT parameter sensitivity. The designed structure has source, drain and gate contact lengths of $1 \mu \mathrm{m}$, a gate-source distance of $2 \mu \mathrm{m}$ and a gate-drain distance of $15 \mu \mathrm{m}$. A gate field plate of $3 \mu \mathrm{m}$ is added at drain side. Contrary to other studies [5] [6], the deep ionization energy of the $\mathrm{Mg}$ dopant is not considered, which means that this region presents an "equivalent" uniform doping profile. Comparative simulations (not presented) with the use of the "incomplete ionization" model present similar results in terms of threshold voltage. Two cases were analyzed: the one with the gate metal directly on top of the P-GaN region, and the other with an insulator between them (Fig. 1).

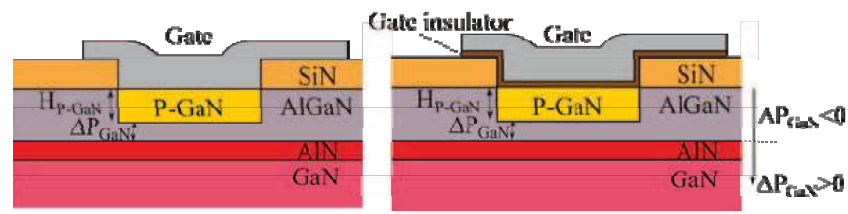

Fig. 1. Gate detail of the proposed structure with metal on P-GaN (left) and with gate insulator on top of P-GaN (right)

First simulations were performed on structures with metal on $\mathrm{P}-\mathrm{GaN}$. Band diagram through the gate at $0 \mathrm{~V}$ for different $\mathrm{AlGaN}$ thicknesses below the gate is presented in

Fig. 2. The etched AlGaN effect can be seen on the conduction band profile, especially at $\mathrm{GaN}$ side. Negative $\Delta \mathrm{P}_{\mathrm{GaN}}$ values means that the remaining $\mathrm{AlGaN}$ layer under the gate provides higher polarization charge to deplete, that finnaly results to lower threshold voltage.

Simulation results of the threshold voltage variations as a function of the P-GaN doping are represented in Fig. 3. When considering ohmic contact, no depletion appears on P-GaN, that can be confirmed by the absence of band bending on

Fig. 2, so the threshold voltage is independent on P-GaN doping concentration. On the contrary, the Schottky contact puts the energy bands downward for lower values of doping concentration, while only high doping values will pin the Fermi 
level close to the valence band. Therefore, the threshold voltage variation is related to the depletion thickness on P-GaN.

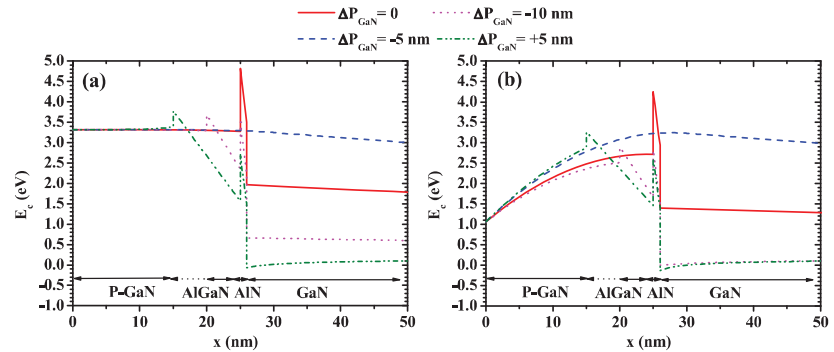

Fig. 2. Conduction band energy profile through the gate for different $\Delta \mathrm{P}_{\mathrm{GaN}}$ values for ohmic (a) and Schottky (b) gate contact.

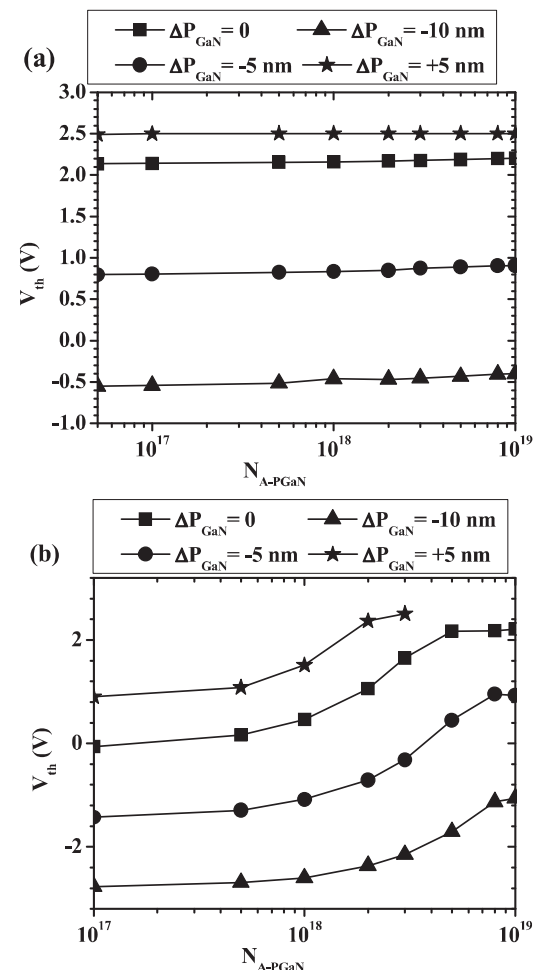

Fig. 3. Threshold voltage as a function of $\mathrm{P}-\mathrm{GaN}$ doping concentration for different $\Delta \mathrm{P}_{\mathrm{GaN}}$ values when the gate contact is defined ohmic (a) and Schottky (b).

For the analysis of the structure with a gate insulator, the material used as insulator as well as its thickness have to be considered. Materials such as $\mathrm{SiO}_{2}$ or $\mathrm{Al}_{2} \mathrm{O}_{3}$ are promising due to their higher bandgap and electron affinity [7], which means an increase in the conduction band continuity with the P-GaN. However, the lower relative permittivity of $\mathrm{SiO}_{2}$ is not favourable in terms of electrical characteristics since it gives lower transconductance as represented in Fig. 4. Moreover, it has been demonstrated that $\mathrm{SiO}_{2}$ induces high density of surface states with GaN [8].

Threshold voltage variations with P-GaN doping concentration for different insulator materials and thicknesses are presented in Fig. 5. Interface states density has been inserted, based on extracted values for structures with the $\mathrm{Si}_{3} \mathrm{~N}_{4}$ layer deposited on P-GaN by LPCVD. These values are expected to change with the insulator material and its deposition method.

Results from structures with insulator show similar trends that previously observed. The additional layer of dielectric absorbs more or less electric field when a gate voltage is applied, depending on its thickness and permittivity, enhancing by the way the threshold voltage variation with doping concentration, which means that the threshold voltage presents stronger voltage variations with $\mathrm{P}-\mathrm{GaN}$ doping. If high P-GaN doping concentration can be demonstrated, high positive threshold voltage is achievable.

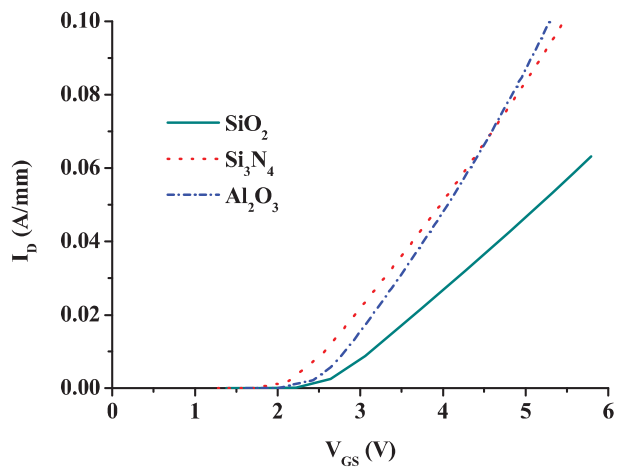

Fig. 4. Transfer characteristics $I_{D}\left(V_{G S}\right)$ of HEMT with different gate insulators of $30 \mathrm{~nm}$ thick.
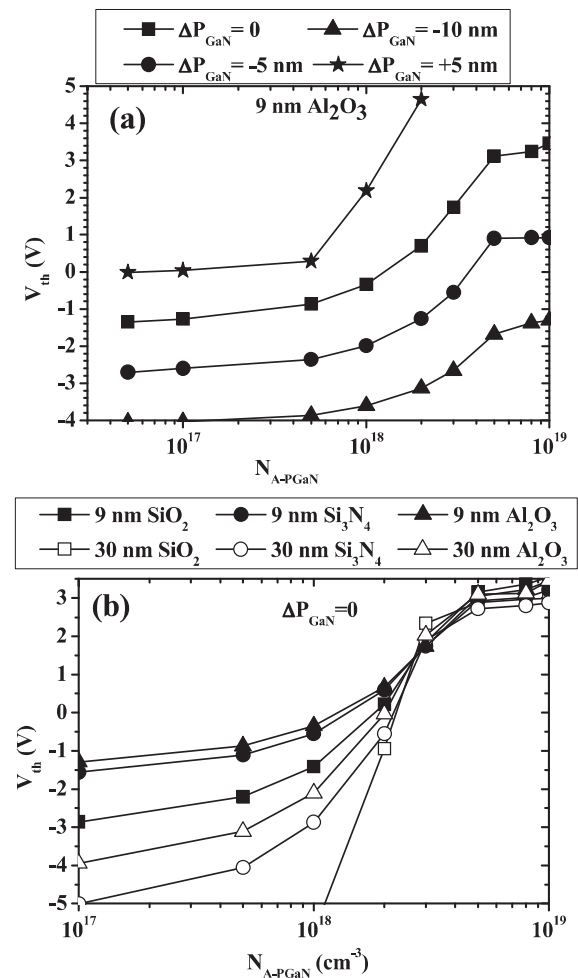

Fig. 5. Threshold voltage as a function of doping concentration for different parameters: (a) P-GaN distance $\left(\Delta \mathrm{P}_{\mathrm{GaN}}\right)$ from AlN surface for $9 \mathrm{~nm}$ of $\mathrm{Al}_{2} \mathrm{O}_{3}$ and (b) different insulator materials and thicknesses. 


\section{GATE RECESS PROCESS}

A fabrication process of the presented device was conducted in order to validate the simulation results previously detailed. The AlGaN/GaN HEMT layers were grown by metal organic chemical vapor deposition (MOCVD) on Si: the epilayer stacking is composed of an alternation of $\mathrm{AlN} / \mathrm{GaN}$ layers, followed by a $1.5 \mu \mathrm{m}$ GaN, $1.5 \mathrm{~nm}$ AlN interface enhancement layer, a $25 \mathrm{~nm} \mathrm{Al}_{0,3} \mathrm{GaN}_{0,7}$ layer and a $10 \mathrm{~nm} \mathrm{SiN}$ cap layer.

Before the gate recess, $50 \mathrm{~nm}$ of $\mathrm{Si}_{3} \mathrm{~N}_{4}$ and $100 \mathrm{~nm}$ of $\mathrm{SiO}_{2}$ were deposited on the epitaxial layers, by LPCVD and ICPECVD respectively (Fig. 6.a) The role of $\mathrm{Si}_{3} \mathrm{~N}_{4}$ is to conserve the $2 \mathrm{DEG}$ density and the $\mathrm{SiO}_{2}$ one is to prevent the growth of the $\mathrm{P}-\mathrm{GaN}$ outside the gate region. The gate is then opened through the etching of three materials: $\mathrm{SiO}_{2}$ and $\mathrm{Si}_{3} \mathrm{~N}_{4}$ were both removed by $\mathrm{CHF}_{3} / \mathrm{O}_{2} \mathrm{ICP}$ plasma and $\mathrm{AlGaN}$ by $\mathrm{Cl}_{2}$ RIE dry etching (Fig. 6.b). This step is pursued by localized $\mathrm{MBE}$ epitaxy of a P-GaN layer into the gate region (Fig. 6.c). The $\mathrm{SiO}_{2}$ masking layer is removed thereafter by wet etching (Fig. 6.d)

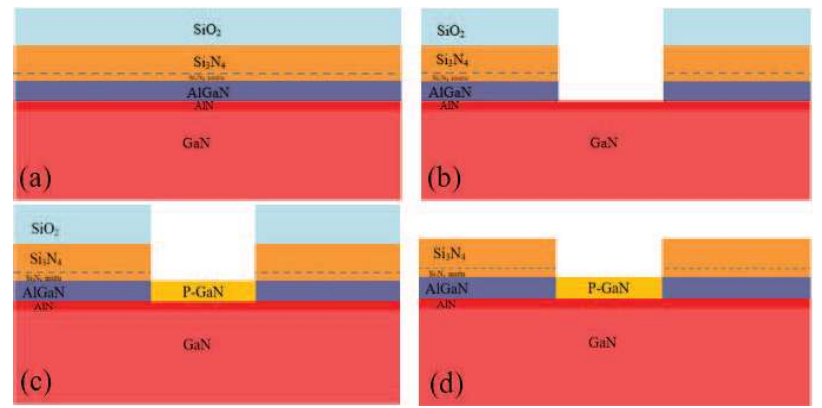

Fig. 6. Schematic process flow of the localized regrowth of $\mathrm{p}-\mathrm{GaN}$ on the gate region. (a) Succession of the epitaxial layers on the $\mathrm{Si}$ substrate; (b) gate recess by dry plasma etching $\left(\mathrm{CHF}_{3} / \mathrm{O}_{2}\right.$ for $\mathrm{Si}_{3} \mathrm{~N}_{4}$ and $\mathrm{SiO}_{2}, \mathrm{Cl}_{2}$ for $\left.\mathrm{AlGaN}\right)$ (c) P-GaN regrowth by $\mathrm{MBE}$ with a $\mathrm{Mg}$ doping; (d) $\mathrm{SiO}_{2}$ removal by wet etching.

\section{A. AlGaN etching}

For the gate recess, inductively coupled plasma or reactive ion etching (ICP-RIE) are the most used techniques owing to their anisotropy etching and efficiency. However, several requirements must be fulfilled when using these techniques such as a smooth surface morphology and a low damage. As mentioned before, a normally-off $\mathrm{P}-\mathrm{GaN}$ technology requires the use of a thin AlGaN barrier layer $(25 \mathrm{~nm})$, therefore the etching rate has to be well-controlled in order to preserve the $2 \mathrm{DEG}$ properties. Selectivity is a very important factor in mastering etching rate: it depends on several parameters such as gas chemistry, chamber pressure and temperature. To the best of our knowledge, there is no selective recipe for AlGaN etching and the etch rate strongly depends on plasma conditions. The majority of AlGaN etching processes are based on chlorine as a principal etching agent: the chlorinecontaining reactant may be boron trichloride $\left(\mathrm{BCl}_{3}\right)$, chlorine $\left(\mathrm{Cl}_{2}\right)$, or a mixture of the two gases [9].

In the present work, a $\mathrm{Cl}_{2}$-based etching was carried out in a RIE plasma etch system for the AlGaN gate recess. The etching conditions were the same as reported by D. Buttari et al. [10]: $\mathrm{RF}$ power $=60 \mathrm{~W}$, pressure $=5 \mathrm{mTorr}$ and
$\mathrm{Cl}_{2}$ flow $=10 \mathrm{sccm}$. The wafer was patterned using ECI 3012 photoresist of $1.1 \mu \mathrm{m}$ thick. The removal of the photoresist mask, after etching, was performed by acetone and isopropanol (IPA), followed by DI water and $\mathrm{O}_{2}$ plasma $(800 \mathrm{~W})$. However, further cleaning was necessary for removing the photoresist post-etch residues remaining on the $\mathrm{AlGaN}$ layer: it will be discussed later. Etch depths were measured by transmission electron microscopy (TEM) and determined to be about $6 \mathrm{~nm}$, $19 \mathrm{~nm}$ and $21 \mathrm{~nm}$ for $25 \mathrm{~s}, 35 \mathrm{~s}$ and $45 \mathrm{~s}$ etching times respectively. A FIB sectional view of the gate after etching is presented in Fig. 7 for $35 \mathrm{~s} \mathrm{AlGaN} \mathrm{etching.}$

The use of a medium RIE power $(<100 \mathrm{~W})$ and the consequent slow etch rate allowed an accurate control of AlGaN thinning. Times lower than $25 \mathrm{~s}$ have not been tested because of the eventual presence of a thin surface oxide layer formed before the etch, that can give rise to a dead time by inhibiting etch at the beginning [11]. Above $45 \mathrm{~s}$, the AlGaN is completely etched as well as the underlying layers, AlN and part of GaN.

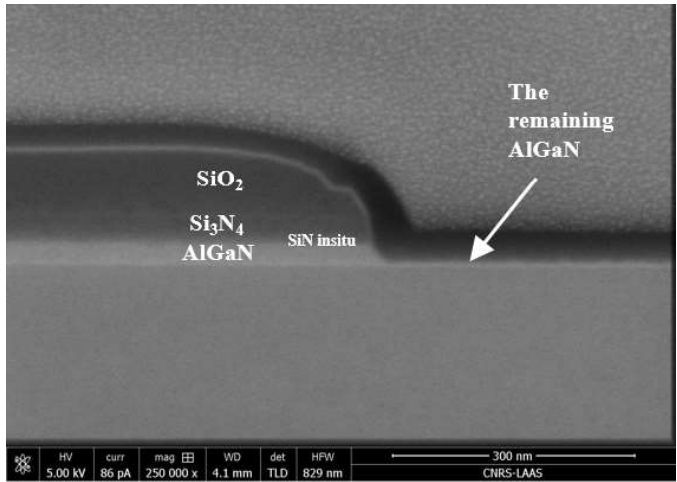

Fig. 7. Picture of FIB cut after the gate recess for RIE AlGaN etching of $35 \mathrm{~s}$

\section{B. Surface roughness}

The root means square roughness RMS measured by AFM on a $2 \times 2 \mu \mathrm{m} 2$ windows before and after etching are respectively $0.43 \mathrm{~nm}$ and $1.22 \mathrm{~nm}$ as shown in Fig. 8. The AlGaN surface observed after a partial etching of $25 \mathrm{~s}$ exhibited a RMS three times higher than the non-etched $\mathrm{AlGaN}$ one. It is very difficult to compare these values to those of literature because the roughness after etching depends on the as-grown surface roughness and the etching parameters. However, the obtained values remain in the range of values reported in literature [12]

It has been proved that the RMS roughness of the etched $\mathrm{AlGaN}$ can be strongly affected by oxidation during plasma etching; the in-situ produced aluminum oxides may provide a self-mask effect [13]. Given that the bond energy of Al-O $(21.2 \mathrm{eV} /$ atom $)$ is higher than that of Al-N $(11.52 \mathrm{eV})$ and Ga-N $(8.92 \mathrm{eV}), \mathrm{AlGaN}$ etch would be limited by the formation of the aluminum oxide. Therefore, the nonuniformity of the aluminum oxide distribution will cause roughness on the etched surface. The addition of an appropriate quantity of $\mathrm{BCl}_{3}$ to the plasma mixture could help to improve the smoothness of the etched surface. Indeed, $\mathrm{BCl}_{3}$ reacts with oxygen to form some $\mathrm{BCl}_{\mathrm{x}} \mathrm{O}_{\mathrm{y}}$ gases which could facilitate the removal of the oxygen remaining into the chamber [14]. 

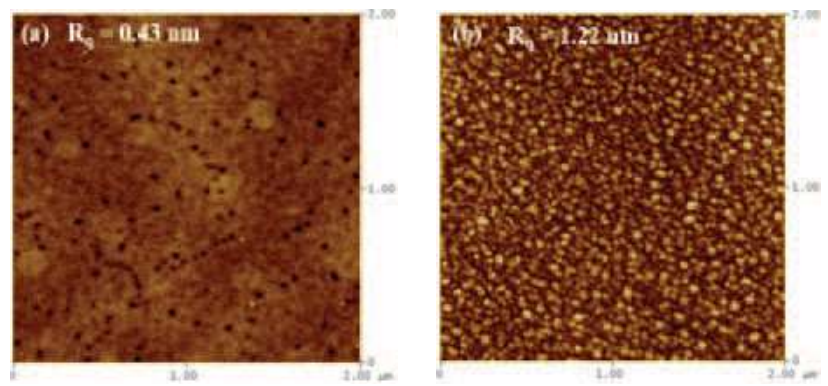

Fig. 8. AFM surface images of the AlGaN (a) before etching, (b) after $\mathrm{Cl}_{2}$ - $\mathrm{RIE}$ etching for $25 \mathrm{~s}$ : $\mathrm{RF}$ power $=60 \mathrm{~W}$, pressure $=5 \mathrm{mTorr}$ and $\mathrm{Cl}_{2}$ flow $=10 \mathrm{sccm}$.

\section{Post-etch residues}

After the resist removal, we observed some residues on the etched surface that were very difficult to eliminate by conventional wet stripping methods. The SEM image in Fig. 9.a shows a veil residue on the etched region. These residual impurities are inherent by-products of the $\mathrm{Cl}_{2}$-based etch process. They are probably formed by a mixture of species stemming from the plasma ions, the photo-resist mask and the etched materials $\left(\mathrm{SiO}_{2}, \mathrm{Si}_{3} \mathrm{~N}_{4}\right.$ and $\left.\mathrm{AlGaN}\right)$, which prevents dissolution by solvents. Several experiments conducted to remove these tenacious post-etch residues by common chemical strippers were ineffective [15]. The selected solution consists of UV insolation of the wafer followed by a developing step. The efficiency of the after-etching cleaning can be observed in Fig. 9.b.
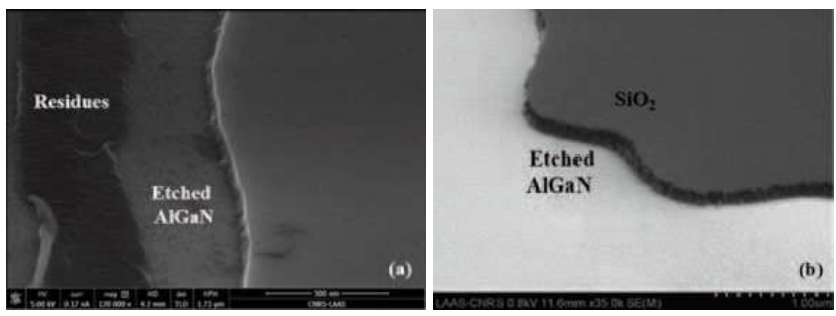

Fig. 9. SEM image showing (a) post-etch residues after the resist removal by acetone, isopropanol and DI water followed by $\mathrm{O}_{2}$ plasma $(5 \mathrm{~min}, 800 \mathrm{~W})$; (b) the removal of the post-etch residues by UV insolation and development after etching.

\section{CONCLUSION}

In this work, a new design of a normally-off HEMT was proposed. The introduction of a P-GaN layer on the $\mathrm{AlGaN} / \mathrm{GaN}$ heterostructure under the gate contact allows the normally-off functionality. The simulations were carried out in two cases: metal on P-GaN (ohmic and Schottky) and gate with insulator for different recess depths and P-GaN doping concentrations. High threshold voltages can be achieved by reducing the thickness of the remaining $\mathrm{AlGaN}$. With the ohmic contact, the threshold voltage is independent on P-GaN doping concentration, contrary to the Schottky one. With the gate insulator structure, the electrical performance depends on the type of insulator and its thickness. Then, a focus on the gate recess process, mandatory for the realization of such devices, was also detailed in this work. A precise AlGaN etching was achieved by adjusting $\mathrm{Cl}_{2}$-RIE etching parameters. The roughness surface after etching was three times higher than the non-etched one but remains acceptable for a RIE mode. Some post-etch residues were found on the etched AlGaN surface and were removed by UV insolating and developing steps. The work of realization oh the whole fabrication process of the $\mathrm{AlGaN} / \mathrm{GaN}$ HEMT is underway in order to demonstrate the normally-off behavior of such a device.

\section{ACKNOWLEDGMENT}

This work was partly supported by LAAS-CNRS micro and nanotechnologies platform member of the French RENATECH network.

\section{REFERENCES}

[1] K. J. Chen et al. "Physics of fluorine plasma ion implantation for GaN normally-off HEMT technology," 2011, pp. 19.4.119.4.4, doi: 10.1109/IEDM.2011.6131585.

[2] Y.-L. He et al., "Recessed-gate quasi-enhancement-mode AlGaN/GaN high electron mobility transistors with oxygen plasma treatment," Chin. Phys. B, vol. 25, no. 11, p. 117305 , Nov. 2016, doi: 10.1088/1674-1056/25/11/117305.

[3] H. Okita et al., "Through recessed and regrowth gate technology for realizing process stability of GaN-GITs," in 2016 28th International Symposium on Power Semiconductor Devices and ICs (ISPSD), Prague, Czech Republic, 2016, pp. 23-26, doi: 10.1109/ISPSD.2016.7520768

[4] Y. Zhong et al., "Effect of Thermal Cleaning Prior to p-GaN Gate Regrowth for Normally Off High-Electron-Mobility Transistors," ACS Appl. Mater. Interfaces, vol. 11, no. 24, pp. 21982-21987, Jun. 2019, doi: 10.1021/acsami.9b03130.

[5] L. Efthymiou, G. Longobardi, G. Camuso, T. Chien, M. Chen, and F. Udrea, "On the physical operation and optimization of the p-GaN gate in normally-off GaN HEMT devices," Appl. Phys. Lett., vol. 110, no. 12, p. 123502, Mar. 2017, doi: $10.1063 / 1.4978690$

[6] I. Hwang et al., "p-GaN Gate HEMTs With Tungsten Gate Metal for High Threshold Voltage and Low Gate Current," IEEE Electron Device Lett., vol. 34, no. 2, pp. 202-204, Feb. 2013, doi: 10.1109/LED.2012.2230312.

[7] J. Robertson and B. Falabretti, "Band offsets of high $\mathrm{K}$ gate oxides on III-V semiconductors," J. Appl. Phys., vol. 100, no. 1 , p. 014111, Jul. 2006, doi: 10.1063/1.2213170.

[8] T. Hashizume, S. Ootomo, T. Inagaki, and H. Hasegawa, "Surface passivation of GaN and GaN/AlGaN heterostructures by dielectric films and its application to insulated-gate heterostructure transistors," J. Vac. Sci. Technol. B Microelectron. Nanometer Struct., vol. 21, no. 4, p. 1828, 2003 , doi: $10.1116 / 1.1585077$

[9] W. Yang, T. Ohba, S. Tan, K. J. Kanarik, J. Marks, and K. Nojiri, "Atomic Layer Etching of $\mathrm{GaN}$ and Other III-V Materials," US 2016/0358782 A1, 2016.

[10] D. Buttari et al., "Systematic characterization of $\mathrm{Cl}_{2}$ reactive ion etching for improved ohmics in AlGaN/GaN HEMTs," IEEE Electron Device Lett., vol. 23, no. 2, pp. 76-78, Feb. 2002, doi: 10.1109/55.981311.

[11] D. Buttari et al., "Origin of etch delay time in $\mathrm{Cl} 2$ dry etching of AlGaN/GaN structures," Appl. Phys. Lett., vol. 83, no. 23, pp. 4779-4781, Dec. 2003, doi: 10.1063/1.1632035.

[12] G. Greco, F. Iucolano, and F. Roccaforte, "Review of technology for normally-off HEMTs with p-GaN gate," Mater. Sci. Semicond. Process., vol. 78, pp. 96-106, May 2018, doi: 10.1016/j.mssp.2017.09.027.

[13] Z. Gao, M. F. Romero, and F. Calle, "Etching of AlGaN/GaN HEMT structures by Cl2-based ICP," p. 4.

[14] Y. Han et al., "Nonselective and smooth etching of GaN/AlGaN heterostructures by $\mathrm{Cl} 2 / \mathrm{Ar} / \mathrm{BCl} 3$ inductively coupled plasmas," J. Vac. Sci. Technol. Vac. Surf. Films, vol. 22, no. 2, pp. 407412, Mar. 2004, doi: 10.1116/1.1641054

[15] G. Levitin, C. Timmons, and D. W. Hess, "Photoresist and Etch Residue Removal," J. Electrochem. Soc., vol. 153, no. 7, p. G712, 2006, doi: 10.1149/1.2203096. 